\title{
Abdominal wall reconstruction (AWR): the need to identify the hospital units and referral centers entitled to perform it
}

\author{
Francesco Gossetti $^{1} \cdot$ Linda D'Amore $^{1} \cdot$ Francesca Ceci $^{1} \cdot$ Maria Romana Grimaldi $^{1}$. \\ Paolo Negro ${ }^{1}$
}

Received: 12 October 2016/Accepted: 23 February 2017/Published online: 4 April 2017

(C) Italian Society of Surgery (SIC) 2017

Criteria to identify hospital units and referral centers in Italy entitled to perform major general surgery, such as esophageal, hepato-pancreatic and colo-rectal surgery were recently proposed [1]. The role of indicators of effectiveness and quality of care, and dramatic innovations in modern surgical subspecialty concur with this proposal [2]. Furthermore there is a robust evidence of improved outcomes of patients treated by specialist multidisciplinary teams.

Abdominal wall reconstruction (AWR) for primary or incisional hernia remains a challenging problem for primary care physicians, surgeons, and patients. Cochrane collaboration places the number of AWRs performed in Europe at about 400,000/year and at 300,000/year in USA [3]. In USA this number is expected to increase of 11,000 procedures each year in the near future. Taking into account the number of repairs performed in 2006, the total estimated procedural cost for AWR was US \$3.2 billion [4]. We personally calculated that 40,000 AWRs (ICD-9 procedural code 53.51, 53.61, 53.59, 53.69) were performed in Italy in 2014 with an estimated cost of 200 million euro, without taking in account economic costs to society including time lost for work and chronic disability (associated with hernias). Approximately a quarter of all incisional hernia repairs needs a reoperation, even with the use of meshes, and the recurrence exponentially increases with subsequent repairs [5]. This could cause significant further rises in healthcare costs mainly if technologically

Francesco Gossetti

gossetti@tiscalinet.it

1 Complex Operative Unit of Abdominal Wall Surgery, Department of General Surgery and Specialties "Paride Stefanini", Sapienza University of Rome, Viale del Policlinico 155, 00161 Rome, Italy advanced meshes or biologic implants are required [6]. In USA each $1 \%$ reduction in hernia recurrence would result in a US \$32 million yearly savings in procedural cost alone. Moreover, other complications, such as surgical site occurrence (SSO), mainly the surgical site infection (SSI), length of hospital stay and quality of life should be taken in account. The cost for an outpatient AWR rises from US $\$ 16,000$ to 65,000 and 82,000 , in cases of SSI and mesh infection, respectively $[4,7,8]$.

Over the last 20 years a great number of innovations both in operative techniques and technologies have revolutionized surgical treatment.

New reconstructive procedures, including component separation, gained popularity with the additional potential benefit of restoring functionality of the abdominal wall. Furthermore, laparoscopic ventral hernia repair (LVHR) improves patient-centered outcomes and represents a viable option in selected cases [9]. Mesh repair significantly reduces the number of recurrences but it needs a strong knowledge of the characteristics of devices, more and more largely proposed on the market [10-12]. Careful matching of patient characteristics and surgical techniques in the choice of prosthetics could minimize postoperative complications and readmissions [13]. In conclusion, it seems inevitable that surgeons are specializing in abdominal wall surgery to an increasing extent [5].

Are AWRs "complex" enough to warrant hospital units and referral centers entitled to perform them? Despite the development of prosthetic techniques, results following abdominal hernia repair are not so good as expected, in term of recurrence and wound complications. Numerous factors should be taken in account, including that in several cases of ventral hernia the best technique and the proper device have not been utilized [5]. This principally happens in case of complex abdominal wall hernias, when clear criteria of 
definition, such as the size and location of the defect, contamination and soft tissue conditions, patient history and risk factors, clinical scenario, are mandatory [14]. So it is difficult to argue that AWR is not complex enough to warrant specialization. AWR is clearly not a minor surgery. It is a major surgery requiring long operative times, skilled surgeons with high volume experience in complex cases, a multidisciplinary approach and risk stratification models to reduce complications and mortality rate [15].

Recently, Aquina et al. [16] reported that surgeon's volume experience plays a significant role in outcomes and costs of incisional hernia repair. On the basis of SPARCS (Statewide Planning and Research Cooperative System) database of New York State $(18,167$ incisional hernia repairs), the study demonstrated that surgeons performing an average of $\geq 36$ repairs/year had significantly lower reoperation rates, operative time and downstream charges. Moreover, for every increase in volume of ten cases per year, there was a significant reduction of recurrence rate. The study did not include LVHR or more complex open hernia repairs with component separation or abdominal wall reconstruction, for which a stronger volume-outcome relationship for hernia recurrence is expected.

In 2013, Colavita et al. [17] investigated trends and outcomes from high-volume and low-volume centers for inpatients ventral hernia repair in USA and argued for regionalization and formation of centers of excellence. The establishment of comprehensive hernia centers for hernia repair has led to a substantial increase in surgical volume, complexity and financial benefits [18]. This may reflect the referral of more complex ventral hernia repairs to high volume centers. Sanders et al. [5] suggested the creation of regional and national centers for the UK, competent in cases requiring AWR with component separation, parastomal hernia repair, complex abdominal wall reconstruction (cAWR), and closure after laparostomy, or neoplasms.

In Italy, we recently proposed to the Italian Society of Hernia and Abdominal Wall Surgery (ISHAWS) to perform a national inquiry to collect the opinion of its members with regards to the accreditation of centers of excellence. A specific Commission will be subsequently set up (1) to define the criteria to identify hospital units entitled to perform AWR in Italy, on the basis of hospital, volume and organization requirements, and (2) to define an accreditation program, periodic audits included. The results of this work should be presented to the Italian Society of Surgery (SIC) and then sent to the Ministry of Health before being released.

\section{Compliance with ethical standards}

Conflict of interest The Authors declare that they have no conflict of interest.
Research involving human participants and/or animals This article does not contain any studies with human participants or animals performed by any of the authors.

Informed consent None.

\section{References}

1. Bassi C (2016) Surgery in Italy. Criteria to identify the hospital units and the tertiary referral centers entitled to perform it. A proposal for esophageal, hepatic, pancreatic and colo-rectal surgery. Updates Surg 68:115-116

2. Ball CG, Sutherland F, Kirkpatrick AW et al (2010) Dramatic innovations in modern surgical subspecialties. Can J Surg 53:335-341

3. Sauerland S, Walgenbach M, Hababermalz B et al (2011) Laparoscopic versus open surgical techniques for ventral or incisional hernia repair. Cochrane Database Syst Rev 3:CD007781. doi:10.1002/14651858.CD007781.pub2

4. Poulose BK, Shelton J, Phillips S et al (2012) Epidemiology and cost of ventral hernia repair. making the case for hernia research. Hernia 16:179-183

5. Sanders DL, Kinngsnorth AN, Windsor ACJ (2016) Is there a role for hernia subspecialists? Or is this a step too far? Hernia. doi:10.1007/s10029-016-1511-9

6. Reynolds D, Davenport DL, Korosec RL, Roth JS (2013) Financial implications of ventral hernia repair: a hospital cost analysis. J Gastrointest Surg 17:159-167

7. Bower C, Roth JS (2013) Economics of Abdominal Wall Reconstruction. Surg Clin North Am 93:1241-1253

8. Fischer JP, Wes AM, Wink JD et al (2014) Analysis of perioperative factors associated with increased cost following abdominal wall reconstruction. Hernia 18:617-624

9. Awaiz A, Rahman F, Hossain MB et al (2015) Meta-analysis and systematic review of laparoscopic versus open mesh repair for elective incisional hernia. Hernia 19:449-463

10. Mathes T, Walgenbach M, Siegel R (2016) Suture versus Mesh repair in primary and incisional ventral hernias: a systematic review and meta-analysis. World J Surg 40:826-835

11. Coda A, Lamberti R, Martorana S (2012) Classification of prosthetics used in hernia repair based on weight and biomaterial. Hernia 16:9-20

12. Klinge U, Klosterhalfen B (2012) Modified classification of surgical meshes for hernia repair based on the analysis of 1000 explanted meshes. Hernia 16:251-258

13. Le D, Deveney CW, Reaven NL (2013) Mesh choice in ventral hernia repair: so many choices, so little time. Am J Surg 205:602-607

14. Slater NJ, Montgomery A, Berrevoet F (2014) Criteria for definition of a complex abdominal wall hernia. Hernia 18:7-17

15. Basta MN, Fischer JP, Wink JD, Kovach SJ (2016) Mortality after inpatient open ventral hernia repair: developing a risk stratification tool based on 55,760 operations. Am J Surg 211:1047-1057

16. Aquina CT, Kelly KN, Probst CP (2015) Surgeon volume plays a significant role in outcomes and cost following open incisional hernia repair. J Gastrointest Surg 19:100-110

17. Colavita PD, Walters AL, Tsirline VB et al (2013) The regionalization of ventral hernia repair: occurrence and outcomes over a decade. Am Surg 79:693-701

18. Williams KB, Belayansky I, Dacey KT et al (2014) Impact of the establishment of a specialty hernia referral center. Surg Innov 21:572-579 